\title{
Dialogic accounting through popular reporting and digital platforms
}

\section{Giuseppe Grossi}

Department of Business Administration, Kristianstad University, Sweden, Department of Accounting and Economic Analysis, Nord University, Norway and Department of Accounting, Kozminski University, Poland, and

Paolo Pietro Biancone, Silvana Secinaro and Valerio Brescia Department of Management, University of Turin, Italy
Popular reporting and digital platforms

\begin{abstract}
Purpose - The purpose of this study is to explore the usefulness of popular reporting (PR) in an Italian city as a dialogic accounting tool for promoting citizens' engagement with digital platforms. This study aims to contribute to the debate on democratic accounting technologies with a focus on PR and digital platforms, using the theoretical lens of dialogic accounting.
\end{abstract}

Design/methodology/approach - A longitudinal case study is used to analyse the implementation and evolution of PR in the city of Turin, Italy and explore how the city involved its citizens with digital platforms. Findings - This study contributes to the debate on public accountability through dialogic accounting tools. Research limitations/implications - Multiple sources (surveys, interviews and interventionist workshops) are used to analyse Turin, Italy as a longitudinal case study.

Practical implications - This study offers practical reflections for legislators, politicians and public managers who need new knowledge and empirical analysis of the effective implementation of the PR as a tool for dialogue and empowering public accounting to hold continuous dialogue with the citizens.

Originality/value - PR can be considered a useful dialogic accounting tool for politicians, managers and government experts to encourage citizens' engagement in a pluralistic society.

Keywords Dialogic accounting, Public accountability, Digital platforms, Popular reporting, Citizen involvement

Paper type Research paper

\section{Introduction}

High on the new public governance agenda is an increasing interest in involving citizens to improve the legitimacy of government actions (Bingham et al., 2005) and increase democratic governance with dialogic accounting tools (Brown, 2009; Mouffe, 2013). The diffusion of open and transparent financial documents is a starting point for citizen involvement (Gonzalez-Zapata and Heeks, 2015; Manes Rossi et al., 2018). For this reason, scholars, public managers and politicians have started to pay more attention to popular reporting (PR) (GASB, 1992; Yusuf et al., 2013). PR is a communication tool that is placed at

(C) Giuseppe Grossi, Paolo Pietro Biancone, Silvana Secinaro and Valerio Brescia. Published by Emerald Publishing Limited. This article is published under the Creative Commons Attribution (CC BY 4.0) licence. Anyone may reproduce, distribute, translate and create derivative works of this article (for both commercial and non-commercial purposes), subject to full attribution to the original publication and authors. The full terms of this licence may be seen at http://creativecommons.org/ licences/by/4.0/legalcode

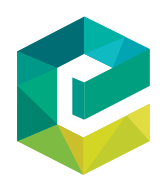

Meditari Accountancy Research Emerald Publishing Limited 2049-372X DOI 10.1108/MEDAR-01-2021-1163 
the highest level of the "pyramid of accountability," as it can provide aggregated data that allow the public administration to account for its use of public resources (AGA, 2010). Traditional PR typically includes financial information targeted to public stakeholders (e.g. citizens, businesses and community groups) who lack a public finance background but do need or desire a less detailed overview of a government's financial activities (Yusuf and Jordan, 2012). Integrated popular reporting (IPR) provides significant non-financial information to respond to the information needs of citizens who have both financial and nonfinancial concerns (Cohen and Karatzimas, 2015; Manes-Rossi, 2019) and allows citizens and stakeholders to conduct more in-depth analyses with this information. To this end, the distribution plan becomes a part of the reporting itself, as it identifies the means, methods and delivery channels (Biondi and Bracci, 2018). However, IPR studies have highlighted a lack of access to information and empirical approaches to guarantee a decentralised government (Del Gesso and Romagnoli, 2020) and financial sustainability (Aversano et al., 2019) through virtuous processes that entail adopting e-democracy tools.

This study explored the usefulness of PR as a dialogic accounting tool to promote citizen involvement in a citizen-centred perspective. Dialogic accounting allows for a more complete expression of the plural nature of contemporary democracies in Western countries. Dialogic accounting has been investigated by numerous accounting scholars, and it offers a more promising way to pursue progressive and social change (Aleksandrov et al., 2018; Bebbington et al., 2007; Bellucci and Manetti, 2017; Brown, 2009; Brown and Dillard, 2015a, 2015b). It aims to support progressive change through the democratisation of accounting. These activities provide support for understanding the concepts and informative priorities that are useful for redefining the information to be given in real time (Brown and Dillard, 2015a).

Manes-Rossi (2019) and Biancone et al. (2018) identified new systems based on systematic data collection and other democratic participation initiatives to improve PR (e.g. focus groups, community assemblies and alternative participatory formats). Over time, the search for transparency and accountability between public administration and citizens has seen the succession of alternative reporting tools: from the sustainability report to the popular report to integrated reporting and then to IPR (Manes-Rossi, 2019; Aversano et al., 2019). This report is configured as being more suitable for integration with other digital participation tools and provides a tool capable of making the citizen a co-producer in public decision policymaking and democratic participation (Manes-Rossi, 2019). Using digital platforms and exploring dialogic accounting can provide an overall view of the differences and priorities amongst the various stakeholders and identifying citizen's perceptions allows for an understanding of which needs should be represented. Internet technology and the Web 2.0 approach allow for the creation and exchange of user-generated content (Bellucci and Manetti, 2017; Secinaro et al., 2021). We used a longitudinal case study to analyse the process of adopting and implementing IPR in the case of Turin, Italy and explore how the city involved its citizens. Multiple sources (surveys, interviews and interventionist workshops) were used to explore the city of Turin as a case study.

\section{Literature on popular reporting}

Despite financial PR already being a widespread tool in the USA and Canada and responding to the need to communicate easily with citizens in a concise way (Biancone $e$ t al., 2016; Clay, 2008; Yusuf and Jordan, 2012), the need for a tool that could present and provide more significant evidence of non-financial information, and therefore, take into account principles now widely used in integrated reporting or "one report," was felt (Eccles and Krzus, 2010). In this regard, IPR represents the integration of two existing and current theories related to this change over time (Cohen and Karatzimas, 2015). The first theory concerns the need for new public relations that are easy for most users, facilitating reading 
more informative reports based on accrual accounting systems; and the second line of thought involves the will of public decision-makers to involve and inform citizens on the type of financing and expenditure being incurred. The IPR, according to the literature, is identified as a possible element that may stimulate effective participation in the citizen's decision-making processes and the balance between transparency, better outcomes by the government and public financial stability (Aversano et al., 2019; Del Gesso and Romagnoli, 2020). Manes-Rossi, in 2019, clarified the differences and similarities between popular financial reporting and IPR by updating the use of the tool. While the PFR aims to fulfil the need for budgetary knowledge and resolve the financial problems of all those concerned, the IPR aims to respond to the information needs of the concerned citizens by representing both financial and non-financial results. The application of the six-capital framework should also guarantee a holistic overview of an entity with simplified disclosure and clearly explain the creation of public value for citizens (Aversano et al., 2019; Cohen and Karatzimas, 2015; Manes-Rossi, 2019). All the actors share a common vision and values, and the strategies, programs and operations derived from this vision and values are designed coherently, adopting a holistic vision of the entity as a whole (Dumay and Dai, 2017; Guthrie et al., 2017). The six-capital framework includes financial, human, social, natural, manufactured and cultural capital (Aversano et al., 2019; Cohen and Karatzimas, 2015; Fordham et al., 2018), and in the IPR, each of these capitals finds different applications (Biancone et al., 2019). The share capital and relationship include the relationships and relative resources between a company and all its stakeholders, including communities, governments, suppliers and customers. In public bodies, it is usually represented by customers who coincide with a representation of the community or the social context and render a description of the sociological and economic characteristics of its citizens or inhabitants, in addition to the relationships with companies and non-profit entities controlled, connected and participated in by the public body, the leading suppliers and other public bodies with which the institution has a relationship. Relational capital also facilitates the understanding of the relationship of responsibility between subjects and can also be represented by the legal or contractual form that binds the public body to its stakeholders (Woolcock and Narayan, 2000). It is possible to proportionally identify the total number of human resources employed between the parent company and the subsidiaries. Similarly, for each sector, it is possible to identify the number of employees and specific skills needed to carry out each activity, the level of education and training received, and professional updates, each of which could be among the elements that can be analysed (Backman, 2014; Kalinina and Valebnikova, 2017; Queiroz and Golgher, 2008). Elements related to human resources are often directly identifiable in the organic plan of the public sector and are compensated by the decisionmaking organisational chart of the body that represents departments and related directions. Natural capital includes resources such as water, fossil fuels, solar energy, crops and carbon sinks, which cannot be replaced and are essential for the functioning of the economy. In public bodies, it is often identifiable in the natural resources of the territory and can also be represented by the forms of sustainable energy used or adopted by the public body (Adger and Whitby, 1993; Ekins et al., 2003). Manufactured capital includes the physical infrastructure or relevant technology, such as equipment and tools. Generally, in public organisations, it is possible to include structures used for public functions such as town halls, registries, schools, structures for social activities and structures for sports activities as manufactured capital. IT structures connected to the services, and other fixed assets such as police cars, means of transport, means of cleaning and waste disposal are also included in it (Gibbon and Pokhrel, 1999). Finally, social or intellectual capital describes the intangible assets associated with the brand and its reputation. Our literature review reveals a lack of 
studies on the dialogic role of IPR and digital platforms useful for promoting citizen participation.

\section{Dialogic potential of popular reporting and digital platforms}

Power (1992) highlighted the limitations of calculative technologies regarding representing the knowledge of human life. This limit was - and still is - linked, in part, to a monologistic reality of the economy in which capitalism restricts the vision that accounting can provide (Cooper and Sherer, 1984). Monologic accounting is limited in that it provides information based only on financial statements that can independently explain the real phenomenon. According to the new public management perspective, the various decision-makers involve citizens and other stakeholders in the decision-making process as well as in assessing the quality, efficiency and effectiveness of public services (Almqvist et al., 2013; Stoker, 2006).

Overcoming the idea of capitalism in Western countries has led to the development of new needs that are linked to a more complex reality. Accordingly, a new accounting approach is needed to encourage democratic debate and take into account the opposing positions of different groups and information needs of all involved actors (Thomson and Bebbington, 2004). Accounting has the power to interpret reality and solve possible social conflicts between groups of actors by ensuring transparency and providing more information (Biancone et al., 2018). The various stakeholders and citizens need to be more involved in the decision-making process to increase their knowledge of the accounting element, which is often absent. This leads to a crisis of accounting and reporting in a monological situation (Lee, 2006). The new approach solves this crisis by taking into account individuals who are situated within "an irreducible plurality of communities and traditions" with multiple, overlapping and sometimes contradictory values and memberships (Brown, 2009; Brown and Dillard, 2015a, 2015b; Dillard and Ruchala, 2005).

Dialogic accounting drives the adoption of tools that allow citizens to participate in the definition and construction of reality rather than emphasising the "discovered reality." It further identifies new technological tools that can be used to support this approach (Brown and Dillard, 2015a, 2015b; Dillard and Ruchala, 2005). However, literature remains focused on participatory budget as a useful element of dialogic accounting tools (Aleksandrov et al., 2018; Brown and Dillard, 2015b), without considering the reporting process, which should provide a complete recognition, explanation and representation of reality according to the literature theory of dialogical accounting. The existing literature has identified that PR can be used to respond to the informative needs of all stakeholders and citizens (Biancone $e$ t al., 2016; Biondi and Bracci, 2018; Brescia, 2019; Manes-Rossi et al., 2019). Table 1 presents the details of applying the various principles of dialogic accounting to PR as elaborated by Brown (2009). The dialogic approach exposes the values and assumptions of accounting models to new ones that create greater information visibility, help all actors recognise reality by facilitating a social redefinition of various public aspects, promote hermeneutically rational decision-making, facilitate dialogue between stakeholders and the accountability of those involved in the process, encourage individuals to discuss social practices and increase the possibility of interpreting a multi-dimensional reality that opposes monologism and preserves future disputes (Brown, 2009).

The post-democratic era identifies a new concept of "publicness" in which the effect of accounting on decision-making and organisational processes as well as the tool must be disseminated and understood as a new current capable of grasping the long-term impact of public services (Steccolini, 2019). This era seeks citizen empowerment tools capable of providing direct democracy or direct management of commons, by relying on digital platforms (Arcidiacono and Reale, 2017; Tenney and Sieber, 2016). These defined 
Principles of dialogic accounting

1 Recognition of multiple ideological orientations

$2 \quad$ Avoiding monetary reductionism

3 Openness about the subjectivity and contestable nature of calculations

4 Enabling access for non-experts

5 Ensuring an effective participatory process

6 Attention to power relationships and their dynamics

$7 \quad$ Recognizing transformative potential

8 Resisting new forms of monologism
Application to popular reporting (PR)

PR represents and gives voice to the conflicting positions of different groups of citizens and politicians, and therefore, to divergent ideologies.

PR provides both quantitative and qualitative information that can satisfy information needs of the various actors and allows for a choice.

PR guarantees greater information to citizens by reducing conflicts related to information asymmetry between government and citizens.

PR gives access to all stakeholders, even those without specific technical skills and knowledge.

The report should be structured by increasing the collection capacity of the need and increasing its diffusion through new distribution channels.

PR is a tool that could be subject to powerful elites who have the ability to

filter out some financial and non-financial results. However, through the certification of information by an external body, it is possible to manage this phenomenon.

PR encourages social actors to be more reflective about the results and facilitate dialogue.

Table 1.

PR should not be a mere political communication tool where politicians and managers provide complete information according to the dialogic rhetoric concept.
Popular reporting and digital platforms

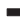


(Chong and Druckman, 2007). There needs to be a common strategy to communicate the full services and objectives achieved in response to the need (Piotrowski et al., 2019). E-participation and the exchange of information on social networks and digital platforms have changed the approach from co-creation to co-design by placing the typology and accessibility of data at the centre. The government can move from a government-centric perspective to a more citizen-centric one by increasing the benefits between the parties; citizens as co-producers can provide their opinions through social media, guaranteeing direct resolution of mutual interests that has a great impact on public value (Alam, 2020; Bracci et al., 2019; Steccolini, 2019). The analysis of social media (such as Twitter) and sentiments increases the administration's narrative and decision-making capacity, although how this approach takes place has not been defined (Akom et al., 2016; Balogun et al., 2020; Chen, 2014). Piotrowski et al. (2019) identified that social media promotes transparency and can be used to manage brand/image strategies, user images and emotions through a continuous exchange. Social media platforms can be used for dialogic purposes in combination with PR, which is useful for communicating the financial and non-financial results/resources to provide citizens with a variety of public services. Bellucci and Manetti (2017) showed that social media can be used to influence managerial choices and understand individuals' opinions on and involvement with specific topics, including stakeholders in the social arena. However, the contribution of the two authors to dialogic accounting does not provide a complete picture that involves both external reporting and stakeholder engagement. E-participation and popular platforms in Europe could increase citizen trust, participation levels and the legitimacy of these platforms among citizens with immediate feedback (Royo et al., 2020).

\section{Research context and methods}

The city of Turin has implemented consolidated financial statements since 2008 (Puddu et al., 2013), and the information that was previously provided through monological reports has changed since 2015 with the introduction of dialogical documents to respond to new needs of decentralised government and to improve citizen involvement. This has ensured the transparency of both the public groups with information provided by the consolidated financial statements and citizen-oriented social reports, making this case worth examining. This case study is particularly significant because Turin is the first Italian city to adopt PR (Biancone et al., 2016). In the first year that Turin implemented PR, the city merely observed the international guidelines and best practices and involved only the city's public managers. The result was a complete report on all the activities conducted by the municipal corporations. Subsequently, a continuous citizen involvement process was initiated to improve the contents of the report based on various stimuli. In 2016, the city administered a survey during the launch and distribution phases of the report. Citizens and civil servants responded to the survey by providing their opinions on the characteristics and content that the city's report should include (Biancone et al., 2016). The recognition of the increase in transparency and real understanding through popular financial reporting towards stakeholders and citizens also came from the auditing firms that recognized Turin's municipality's desire to guarantee citizens access to information and its exchange (Zambo and Beltrachi, 2016).

The first agreement between the municipality and the university aimed to identify best practices in the countries that apply financial PR, and the approach and structure that the report must have. At the same time, the municipality provided continuity to the collaboration between the municipalities, universities and the chartered accountant of Turin on the construction of the consolidated financial statements. The survey results were 
integrated with both observations from the city's institutional social channels and critical indicators of social well-being. This data then provided an indication of each region's information needs, which were prioritised in the construction of the second report. The third edition involved a set of methods. Turin identified the main sectors and municipal corporations based on expenditures, credits, debts and income and used this data for future information collection purposes.

The use of a citizen e-participation platform - Deciditorino.it - made it possible for the city to identify which areas it needed to focus on, as this platform encourages debates and discussions between the local administration and citizens. The Deciditorino.it e-platform allowed the city to collect feedback from various actors and conduct a long analysis. Receiving feedback on the municipality over social media regarding how the citizens perceive certain services allowed the city to collect data on both perceptions of individual services and municipal public groups (Piotrowski et al., 2019). In the third edition (the 2018 report), social indicators were used for the first time to compare the main aspects of the city with other Italian provinces by identifying and providing appropriate benchmarks. Finally, the feedback received during interventionist workshops highlighted the significant need for transparency and accountability. In this experimental phase, the collection of feedback on social media was only partial and involved three sectors at an experimental level (education, safety and public transport). The latest edition, 2019/2020, combines feedback received on the city's social media, involving individual municipal departments and social indicators to represent the context. Social media analysis is transversal to all municipal sectors. The analysis of social media is guaranteed by a new agreement with the Municipality of Turin, which, through lab analysis, integrates the collection and analysis of data through a social media sentiment analysis tool called Talkwalker. The latest version of the report makes extensive use of social media analysis and the relationship between politicians and citizens on social media. The third and fourth editions confirm the agreement between the city of Turin and the university both for the preparation of the consolidated balance sheet and for defining the contents of the report, guaranteeing greater exchange of information and comparison between citizens and municipalities aimed at also mapping the planned political objectives. As mentioned previously, the present empirical research is based on a longitudinal case study of Turin, Italy. We relied on interventionist workshops and semistructured interviews to triangulate the observations and information of PFR and IPR on the institutional site (http://comune.torino.it/bilancio/) (Table 2). The contents and objectives of the interventionist workshops were made public through the proceedings published by the Turin city.

An interventionist approach allows one to explore how the contents included in PR have changed over time. As defined by Baard and Dumay (2020), the interventionist approach adopted does not act on the behaviour of managers and politicians, instead, it influences the decision-making capacity of the subjects to bridge gaps in citizen empowerment and continuous dialogue by developing their skills to increase their decision-making capacity regarding preparation of the consolidated financial statements and reporting of the group

\begin{tabular}{|c|c|c|c|}
\hline Period & Method & Area & \\
\hline 2016 & Questionnaires & Citizens & \\
\hline 2016-2019 & Interviews & Five politicians, six civil servants and six consultants & Table 2. \\
\hline 2016-2020 & Interventionist workshops & Experts and municipal employees & Empirical research \\
\hline 2020 & Follow-up interviews & Three politicians, four public managers and two consultants & methods \\
\hline
\end{tabular}


results obtained. It also provides a greater understanding of the report's role in the exchange of information between accounting players and citizens. Previous researchers have used an interventionist approach to gather both empirical and theoretical evidence (Lukka and Suomala, 2014). By analysing phenomena in field, an interventionist approach can improve theory, allowing one to solve practical managerial problems based on actual case study (Jönsson, 2010). The effectiveness of interventionist research is particularly relevant in the public sector because it is sensitive to the complex reality and problems to be solved (Bracci et al., 2019). In the present study, three authors participated as experts and active actors in the development of PR in the city of Turin.

From 2016 to 2019, semi-structured interviews were conducted with five politicians, six civil servants (managers and staff) and six consultants. The purpose of these interviews was to analyse the implementation of IPR, level of involvement of actors and citizens and role of collected feedback in preparing reports. Follow-up interviews were conducted in 2020 with three politicians, four public managers and two consultants.

\section{Results}

The implementation of IPR was divided into four phases (Figure 1).

In the first phase, the city of Turin voluntarily consolidated and presented the city's post2008 financial statements, aiming to provide an overall picture of the municipality in a monological way. The politicians and managers we interviewed confirmed the following: "First, we thought about what to communicate and how to receive the opinions of the

Figure 1.

Four phases of implementation of IPR

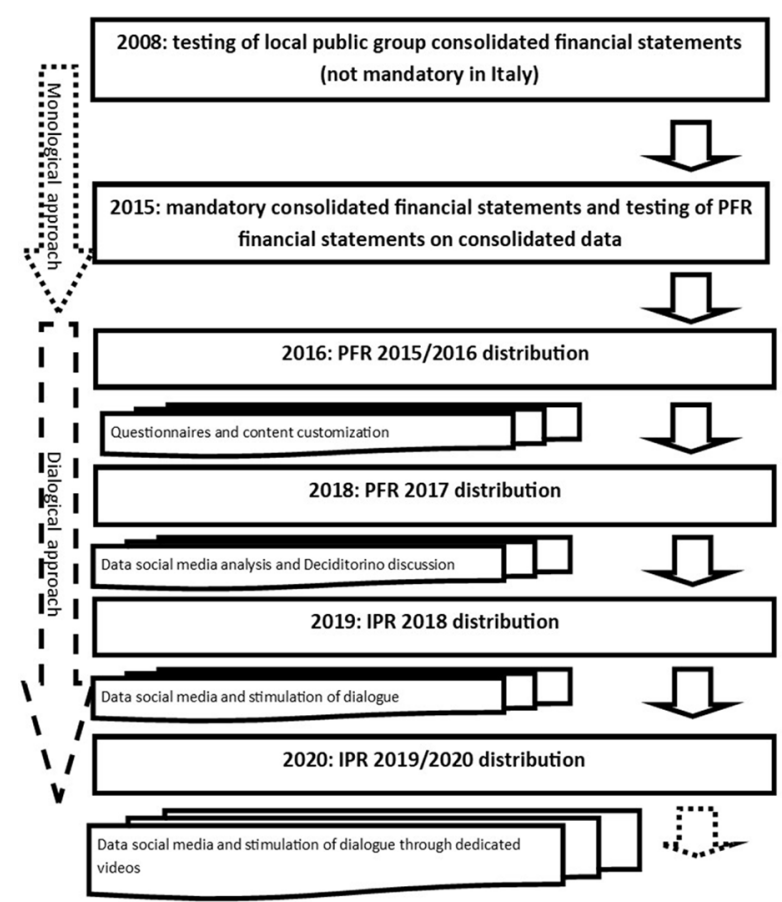

The consolidated financial statements comprise the statement of financial position, the income statement and statement of comprehensive income, the statement of changes in equity, the statement of cash flows and the notes, which include the segment information.

Analysis of the context, analysis, and simplified description of the consolidated financial statements and the municipality's financial commitment, quantitative and qualitative results of the group, dissemination plan, methodological note. (Manes Rossi et al., 2019)

Previous contents

Focus with specific information and feedback to the citizen

orientation to the representation of the six capitals

achievement of political and administrative objectives and future planning (Biancone et al., 2019) 
citizens." Interviewed external experts stated that "popular financial reporting is a useful tool for guaranteeing that citizens will have real transparency, as they can read about the city's performances in terms of financial and non-financial results." In accordance with previous studies (Bebbington et al., 2007; Brown and Dillard, 2015a), the first phase can be considered the monological accounting phase; as an interviewee declared: "The reciprocal exchanges of information between the city and the citizens/external stakeholders were either very limited or absent altogether."

Interviewees indicated that, in the second phase, "the city was more interested in involving citizens." One Torino Municipality politician stated the following: "The second IPR edition was created with the aim to increase dialogue with citizens," adding that "between 2016 and 2017, the dialogic approach was improved in a way that allowed the politicians to respond quickly and effectively to the citizens' information needs by analysing citizen opinions and feedback." For example, the number of pages was considered adequate by citizens concerning a public group's representative needs that carry out numerous activities (Biancone et al., 2016). As shared by one of the interviewees: "Information shared through the city's institutional social channel (Facebook) makes it possible to understand and add communication channels for dissemination (social media), and rethink the graphics and the priority of the contents, which, together with the results of the questionnaire, define the structure of the report (priorities and insights on general municipal sectors and deletion of information." The IPR chapter structure remained almost unchanged in the first two editions. The first chapter introduced the context of the city and the consolidated group of the city of Turin, and the second chapter represented the value of a consolidated public group. The third chapter presented the qualitative and quantitative terms of the public services realized by this consolidated group. The fourth chapter showed a resume of other entities and companies, while the fifth chapter was essential because it explained the methods used to realize the document. The last chapter linked the will to realize a common knowledge of the fulfilment of the public group and public comparison research to publication of results. It was summarized in a plan of dissemination.

In the third phase, "The city considered citizens' information needs and other local stakeholders before publishing the report," as expressed by a major stakeholder. A technical staff member of the councillor and mayor declared that: "Popular reporting is a useful tool to allow citizens to read the group's performance and give feedback." In 2018, a report was published and a series of participatory actions were implemented to create a permanent dialogic approach, resulting in the creation of a report that considered citizens' feedback collected via the DecidiTorino platform. An interviewee elaborated: "We chose a digital platform that could allow for real-time perceptions of information needs by providing direct feedback to the citizens on specific sector issues and the choices made before the report is released." However, the failure of the DecidiTorino's platform to present a complete picture of the debated issues was also recognized in this phase; this failure was a result of the platform providing the viewpoints of only those residents who were active on the platform. As stated by an interviewee: "The e-platform Deciditorino.it had some limitations; there was also the impossibility of having a complete vision of the need and active citizens, and inequality between those who can participate on digital platforms and those limited in terms of the available tools, knowledge, and digital education." Additionally, a manager of Torino Municipality stated: "We moved to the social dimension, experimenting with an interactive platform. Social channels are the most effective way to encourage involvement."

Approach to collect sentiments produced on social media directly or indirectly by citizens (Tenney and Sieber, 2016) has replaced the unsuccessful direct debate generated by Deciditorino.it. 
Interviews conducted in the third IPR phase highlighted that the public manager had collected information on the problems or events that triggered negative feelings and feedback. Talkwalker identified and analysed debate on the main information shared either by the municipal administration on social media or by newspapers published on social media. Our results highlight how the immediate response of each sector's political staff increases and stimulates the comparison and specificity of information that the citizens intend to reach. The last phase was based on the approach identified in the third experimental phase. The analysis of feedback and comparisons on social media promoted by the political staff guarantees a collection of the specific evidence and information that the citizens need in real-time to form a complete picture of the municipal public group. Thus, in the last phase, the feedback was collected to compose a database of emotions and needs regarding which the report provides specific insights.

Interventionist analysis and public managers' willingness to map the consumption of resources changes the structure of the contents by integrating the IIRC framework and six-capital representation approaches in the report's different sections. The report's contents in subsequent versions identify, in the first chapter, associations between the context of natural reference, social and relationship capital, also referred to as the relationship between the municipality and the municipal public group's companies. Human capital is expressed in proportion to the shares of capital that the city holds in its subsidiaries and is also represented by distributing resources from each public service expressed together with quantitative and qualitative data referring to the manufactured capital. Intellectual capital is expressed by a specific chapter linked to the city's Department of Innovation that recalls the policies adopted and their significant elements. Financial capital is represented by the size of the public group, the allocation of resources by service and the generation of value aimed at budget balance and financial stability. The evolution from PR to IPR is because of a greater representation of and attention to the six capitals, which leads to the representation of specific focuses by service within the report based on citizens' needs. A practical example of collecting sentiments and the incidence of engagement is accessible online (City of Turin, 2019). Voluntary and involuntary involvement through ICT tools has allowed a progressive comparison between actors and citizens over the years (Bartoletti and Faccioli, 2016), evolving the approach to dialogic accounting (Brown, 2009). Furthermore, the variation and personalisation of the report contents have been achieved in response to the evolution of the need, demographic and gender characteristics of the debates, of the oriented themes from media and civic actors to city politics.

\section{Discussion}

The dialogic accounting process finally allowed an exchange of information between citizens, politicians and public managers via social media feedback. Social media analysis also allows politicians and public managers to better understand the citizens' viewpoints relating to the allocation of resources. This type of analysis allows one to gather significant elements related to performance in financial or non-financial data; greater profiles that influence public opinion; feelings related to a sector or a service, identify those that are the most debated or critical in the opinion of interested parties; demographic position; and differentiation by gender. The factors described lead to a possible perception of the complex reality in which a monological approach to accounting undermines the solidity of a social instrument that could change the perception of reality by legitimising and involving the citizens and interested parties in the decision-making process and interpretation of results. 
Brown (2009, pp. 319-320) criticised the depoliticisation of politics and the "difficulty dealing with the conflictual side of pluralist relationships" in deliberative democracy and related accounting. Stated below are the principles of dialogic accounting (Brown, 2009) and their application to IPR in Turin.

\author{
Popular \\ reporting and \\ digital \\ platforms
}

\subsection{Recognition of multiple ideological orientations}

Dialogic accounting (Brown, 2009) suggests that PR and digital platforms should recognize divergent ideological perspectives and extend a "voice" to different stakeholders, as this forms a basis for exploring people's commonalities and differences. The implementation of IPR has allowed the city of Turin to understand multiple ideological orientations, as highlighted by debates on social media among groups of citizens, and stakeholders, and the city administration that supports their recognition. Identification of the citizens and recognition of their needs and ideas were favoured through subdivision into clusters of gender, age, income, inhabited area, profession and members and age of the family unit, stimulating specific and targeted interactions.

\subsection{Avoiding monetary reductionism}

Based on the monetary-reductionism analytical dimension of dialogic accounting, we investigated and analysed whether and how IPR creates diverse quantitative and qualitative information that can help one to make one's own judgements about monetisation, incommensurability and space for trade-offs (Brown, 2009). The current structure of IPR focuses on specific aspects of debate between the administration and political staff by integrating parts of the report or constituting real focuses within each section of the report. General interest and association with specific transversal projects have increased the length of the report in the last two editions with a new chapter that identifies the use of ministerial funds by various municipal sectors.

\subsection{Openness about the subjectivity and contestable nature of calculations}

IPR should recognize that subjectivity is an essential part of the dialogic process and that new "accounts" should be open to being contested and challenged by other stakeholders (Brown, 2009). IPR, by providing quantitative, qualitative and also financial data with the adoption of sensitive analysis tools, allows a response and a survey on specific issues that create "anger or bitterness." IPR is often based on open data, AperTO [1], made available by the city, which guarantees direct access to data, while certifying the flow of information in collaboration with an academic team of experts. The representation of data without a positive or negative connotation in the IPR leads to real subjectivity.

\subsection{Enabling access for non-experts}

Dialogic accounting (Brown, 2009) pointed out the relevance of information being accessible in multi-level ways in IPR, including technically understandable formats available for experiments by non-experts. IPR is widespread with a distribution plan for its express essence as it adopts simple and accessible language, with short sentences and many explanatory figures and images. Images, infographics and definition of terms guarantee accessibility to and transparency of information. The IIRC framework adoption is closely related to the translation of complex information with a narrative approach. Stone and Lodhia (2019) confirmed that this leads to greater accessibility to information. 


\section{MEDAR}

6.5 Ensuring effective participatory process

Dialogic accounting (Brown, 2009) stresses that achieving effective participation in practice provides significant challenges. The IPR ensures a greater understanding of debate topics that evolves over time by modifying the content and focus present in the report. Receiving information and consolidating the main topics of debate are convenient through social media. Figure 2 presents an example of sharing public feedback on the entire document, segmented by the sector of each councillor in 2020, over social media. All the videos associated with each sector are also available at the following institutional link: www.comune.torino.it/bilancio/pop/2019/.

\subsection{Attention to power relationship and their dynamics}

Attention to power dynamics for dialogic accounting is vital to ensure that all groups of citizens are included in the participatory processes and that their priorities are not defined out of technical models (Brown, 2009). Political conflict and lack of trust in the public sector have led to a search for participatory tools such as IPR to overcome issues relating to the partial transparency of information provided. IPR systematises information and data by providing a bridge between citizens, politicians and administrators by increasing citizengovernment engagement and future co-design. Citizens' voices acquire a relevant and powerful role; government and politicians can no longer exempt themselves from paying attention to the community's voice once specific processes of exchange and citizen participation have been systematised (Chen and Chang, 2020; Tenney and Sieber, 2016).

\subsection{Recognizing transformative potential}

Dialogic accounting aims to increase to increase reflexivity between stakeholders and promote a more effective dialogue across groups with diverging interests and values

Figure 2.

Example of dissemination and feedback from citizens: a screenshot of Turin's mayors' Facebook page in 2020

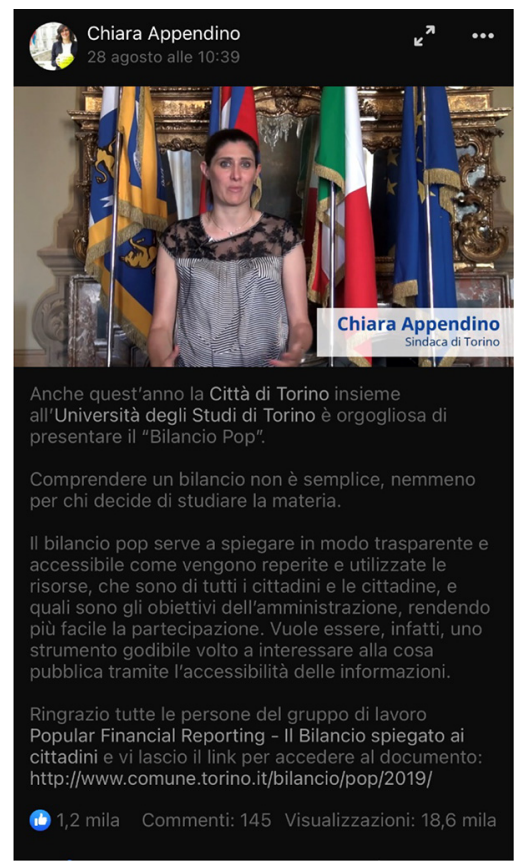


(Brown, 2009). Representing results by mission or project can involve specific interest groups and make public managers aware of changes. The staff of political councillors provides answers and records other questions and observations that follow in a circle of continuous dialogue. Sentiments or noise and semantic annotations associated with continuous debate justified by financial and non-financial data (Alkhammash et al., 2019) could create, through IPR, a virtuous process of information exchange with citizen empowerment and more outstanding management, information and response capacity of politicians and public managers. Views divergent from those of the administration are recorded by the Talkwalker platform, effectively providing disparate views that lead to a reasoned confrontation in reporting. The continuous debate between administration (politicians, public managers) and citizens is in fact balanced by knowledge of the financial allocation, desired outcomes and sharing of the public value generated and detected within the IPR (Bracci et al., 2019). Reports and social media play the role of citizenship school in guiding conscious decisions in the medium to long term (Aversano et al., 2019; Steccolini, 2019). The elements highlighted in Table 1 are respected, leading to financially sustainable decision-making that is also empirically effective and dynamic.

\subsection{Resisting new forms of monologism}

Adoption of social media guarantees a continuous updating of approaches and result in checks that are not based on static reports. Making public administration truly social requires not only an organisational effort in terms of integrated, differentiated and multimedia communication plans but also a change of pace in the vision of digital tools that can help to orient towards a more collaborative space through dialogue. This study demonstrated how the evolution of IPR towards dialogic accounting tool created a space for unheeded stakeholders like citizens (who are ignored in traditional accounting) and allowed the city to tend to a diverse range of conflicting goals and values based on the plurality of the society and the population's feelings and perceptions. New need-oriented perspectives have generated the opportunity to create reports capable of responding to progressive sociopolitical and economic changes with a complete but straightforward language of the sixcapital framework. The dialogic accounting process is currently formalised through new reporting tools linked to progressively evolving contents capable of immediately grasping the citizen's needs and personalising contents to population characteristics (Brown, 2009). The objective of dialogic accounting is not necessarily to reach agreement but rather to promote a richer consideration of complex issues.

\section{Conclusions}

This study reveals that Turin's IPR approach evolved as the city collected and provided more detailed information to better respond to the citizens' needs (Biancone et al., 2016; Biancone et al., 2017). The city's IPR approach started with the publication of a monological document, which indicated that the city hoped to collaborate more with its citizens. Then, based on requests received from the first document, the city moved the dialogue to a specific platform. The social media analysis allowed the dialogue to improve, and the city indicated that its priority was to encourage a dialogue between the public administration and citizens. This analysis led to the city prioritising the release of more detailed information in response to the citizens' needs.

Social media analysis can be considered a tool to promote dialogue between institutions and citizens and take charge of managing the relationship and interaction with citizens. Information through IPR affects and modifies the partial perceptions of feelings on social media relating to the quality of the specific service and the value of the city and its 
subsidiaries. When the structure and contents of IPR are based only on questionnaire responses from a sample of the population, an overall and real-time representation of the issues is not guaranteed. While IPR has made it possible to identify which theoretical and structural elements must be presented to guarantee transparency, accessibility and readability of information, there is still not a recognised method for constructing the contents included in IPR (Biancone et al., 2019; Biancone and Secinaro, 2015; Biondi and Bracci, 2018; Cohen and Karatzimas, 2015; Jordan et al., 2017; Manes Rossi et al., 2018; Yusuf and Jordan, 2012).

Turin built its IPR based on previously undefined approaches and tools, and the city conducted a social media analysis to adapt the contents of its IPR to the citizens' expressed needs. Furthermore, debates on digital platforms often reflect the perceptions of a small percentage of the population and are not even at the sample level; thus, they may not accurately represent citizen needs and perceptions of specific public services. In the digital age, public administration endeavours to improve its services not only through social media but also by monitoring social media to understand any emerging trends. Public administration achieves this by collecting information on user opinions as expressed on posts, publications, shares, likes and so on.

The city of Turin was able to use the social media results to immediately understand that it needed to do more thorough IPR. Therefore, the traditional accounting process is likely to remain tied to the old system of monologic accounting, which offers a limited portrayal of reality and provides documentation that insufficiently represents the social context of the municipalities. Instead, if Turin's IPR focuses on a careful analysis of the main elements that create debate and negative public reactions, it is possible to effectively provide transparent answers and accountability to citizens who are often not able to grasp the whole picture owing to a lack of sufficient information.

This study contributes to the debate on the positive impact of digital citizen involvement in dialogic accounting tools such as IPR to enhance democratic governance (Brown, 2009; Brown and Dillard, 2015a, 2015b). The study also contributes to the existing literature on IPR, demonstrating how IPR can be used to promote citizens' involvement and the administration's will to create and maintain a dialogue with its citizens (Aversano et al., 2019; Cohen and Karatzimas, 2015; Manes-Rossi et al., 2020). The case of Turin shows that IPR enables the citizens to provide feedback, gain an understanding of certain complex situations (e.g. when there is a conflict between groups of citizens or between the administration and citizens) and obtain complete information on issues that have either been incompletely addressed or otherwise distorted on social media (Liu, 2015; Piotrowski et al., 2019). In the case of Turin after the publication of the IPR, citizens seem more engaged in the council decisions and in the political life and regularly provide feedback through social media on information received. Our findings highlight that cities should be able to respond to citizens' comments and feedback and that cities can change their communication strategies by using IPR to improve transparency to present citizens with a more realistic picture of the administration. IPR can be a useful dialogic accounting tool for politicians, managers and government experts to capture citizens' needs in a pluralistic society. This study also has several practical implications as it offers operational elements of reflection for legislators, politicians and public managers who need knowledge and empirical analysis of the effective implementation of the IPR as a tool for dialogue and empowering public accounting to hold continuous dialogue with the citizens (Karatzimas, 2020). This study confirms the usefulness of IPR as a tool of a dialogic accounting to promote a citizen-centric perspective through a continuous process that starts with the discussion of the citizens' information needs and ends after a process of involvement through digital platforms with a 
broader public accountability on outputs and outcomes (Bracci et al., 2019; Steccolini, 2019). This study showed how the evolution of IPR towards dialogic accounting tool created a space for unheeded stakeholders usually ignored by traditional accounting tools and allowed politicians and public managers to consider a diverse range of conflicting goals and values based on the plurality of the society and the population's needs and perceptions. The main challenges are linked to the diffusion of technology in the reporting tool and how much it will facilitate dialogue and interaction with citizens on public management issue (Secinaro et al., 2021). PR and citizen-centric technology innovation could be the keys to the direct dialogue.

Future studies could analyse the role of internal actors (politicians, accountants, auditors, controllers and consultants) in promoting and implementing dialogic accounting tools such IPR within public sector organisations. It could be also interesting to investigate the microdynamics involved in (re-)constructing dialogic accounting tools as they are implemented in everyday practices. It could be also interesting to investigate how actual dialogic accounting practices are translated in the public sector (Bracci et al., 2021). In particular, it could be relevant to investigate the contextual factors and internal dynamics and the interactive nature of actors' relationship to institutionalization process of IPR. Moreover, the role of internal political and managerial actors who enable dialogic accounting changes considering their interests, identities, power and search for legitimacy.

\section{Note}

1. http://aperto.comune.torino.it/

\section{References}

Adger, W.N. and Whitby, M.C. (1993), "Natural-resource accounting in the land-use sector: theory and practice", European Review of Agricultural Economics, Vol. 20 No. 1, pp. 77-97.

AGA (2010), "Public attitudes toward government accountability and transparency", available at: www.agacgfm.org/AGA/ToolsResources/CCR/Survey-WhitePaper10.pdf (accessed January, 2021).

Akom, A., Shah, A., Nakai, A. and Cruz, T. (2016), "Youth participatory action research (YPAR) 2.0: how technological innovation and digital organizing sparked a food revolution in East Oakland", International Journal of Qualitative Studies in Education, Vol. 29 No. 10, pp. 1287-1307.

Alam, S.L. (2020), "Many hands make light work: towards a framework of digital co-production to cocreation on social platforms", Information Technology and People, Vol. 34 No. 3.

Aleksandrov, E., Bourmistrov, A. and Grossi, G. (2018), "Participatory budgeting as a form of dialogic accounting in Russia: actors' institutional work and reflexivity trap", Accounting, Auditing and Accountability Journal, Vol. 31 No. 4, pp. 1098-1123.

Alkhammash, E.H., Jussila, J., Lytras, M.D. and Visvizi, A. (2019), "Annotation of smart cities Twitter micro-contents for enhanced citizen's engagement”, IEEE Access, Vol. 7, pp. 116267-116276.

Almqvist, R., Grossi, G., van Helden, G.J. and Reichard, C. (2013), "Public sector governance and accountability", Critical Perspectives on Accounting, Vol. 24 Nos 7/8, pp. 479-487.

Arcidiacono, D. and Reale, G. (2017), "The open data movement: young activists between data disclosure and digital reputation", Partecipazione e Conflitto, Vol. 9 No. 3, pp. 918-948.

Aversano, N., Polcini, P.T., Sannino, G. and Agliata, F. (2019), "Integrated popular reporting as a tool for citizen involvement in financial sustainability decisions", in Caruana, J., Brusca, I., 
Caperchione, E., Chen, S. and Manes Rossi, F. (Eds), Financial Sustainability of Public Sector Entities, Palgrave Macmillan, Cham, Switzerland, pp. 185-205.

Baard, V.C. and Dumay, J. (2020), Interventionist Research in Accounting: A Methodological Approach, Routledge, New York, NY.

Backman, M. (2014), "Human capital in firms and regions: impact on firm productivity", Papers in Regional Science, Vol. 93 No. 3, pp. 557-575.

Balogun, A.L., Marks, D., Sharma, R., Shekhar, H., Balmes, C., Maheng, D., Arshad, A. and Salehi, P. (2020), "Assessing the potentials of digitalization as a tool for climate change adaptation and sustainable development in urban centres", Sustainable Cities and Society, Vol. 53, p. 101888.

Bartoletti, R. and Faccioli, F. (2016), "Public engagement, local policies, and citizens' participation: an Italian case study of civic collaboration”, Social Media + Society, Vol. 2 No. 3, p. 2056305116662187.

Bebbington, J., Brown, J., Frame, B. and Thomson, I. (2007), "Theorizing engagement: the potential of a critical dialogic approach", Accounting, Auditing and Accountability Journal, Vol. 20 No. 3, pp. 356-381.

Bellucci, M. and Manetti, G. (2017), "Facebook as a tool for supporting dialogic accounting? Evidence from large philanthropic foundations in the United States", Accounting, Auditing and Accountability Journal, Vol. 30 No. 4, pp. 874-905.

Biancone, P. and Secinaro, S. (2015), "Popular financial reporting", Un Nuovo Strumento Di Rendicontazione per Le Municipalità, Giappichelli Editore.

Biancone, P., Secinaro, S. and Brescia, V. (2016), "The popular financial reporting: focus on stakeholders-the first European experience", International Journal of Business and Management, Vol. 11 No. 11, pp. 115-125.

Biancone, P., Secinaro, S.F. and Brescia, V. (2017), "The popular financial reporting and gender accountability, the integrated approach in municipalities and public bodies", American International Journal of Contemporary Research, Vol. 7 No. 3, pp. 91-101.

Biancone, P., Secinaro, S., Brescia, V. and Iannaci, D. (2019), "The popular financial reporting between theory and evidence", International Business Research, Vol. 12 No. 7, pp. 45-56.

Biancone, P., Secinaro, S.F., Brescia, V. and Iannaci, D. (2018), "Communication and data processing in local public group: transparency and accountability", International Journal of Business and Management, Vol. 13 No. 10, pp. 20-37.

Bingham, L.B., Nabatchi, T. and O'Leary, R. (2005), “The new governance: practices and processes for stakeholder and citizen participation in the work of government", Public Administration Review, Vol. 65 No. 5 , pp. 547-558.

Biondi, L. and Bracci, E. (2018), "Sustainability, popular and integrated reporting in the public sector: a fad and fashion perspective", Sustainability, Vol. 10 No. 9, p. 3112.

Bracci, E., Biondi, L. and Kastberg, G. (2021), "Citizen-centered financial reporting translation: the preparers' perspective”, Financial Accountability and Management, doi: 10.1111/faam.12298.

Bracci, E., Papi, L., Bigoni, M., Gagliardo, E.D. and Bruns, H.-J. (2019), "Public value and public sector accounting research: a structured literature review", Journal of Public Budgeting, Accounting and Financial Management, Vol. 31 No. 1, pp. 103-136.

Brescia, V. (2019), The Popular Financial Reporting: New Accounting Tool for Italian Municipalities, Vol. 1209, Franco Angeli.

Brown, J. (2009), "Democracy, sustainability and dialogic accounting technologies: taking pluralism seriously", Critical Perspectives on Accounting, Vol. 20 No. 3, pp. 313-342.

Brown, J. and Dillard, J. (2015a), "Dialogic accountings for stakeholders: on opening up and closing down participatory governance”, Journal of Management Studies, Vol. 52 No. 7, pp. 961-985.

Brown, J. and Dillard, J. (2015b), "Opening accounting to critical scrutiny: towards dialogic accounting for policy analysis and democracy", Journal of Comparative Policy Analysis: Research and Practice, Vol. 17 No. 3, pp. 247-268. 
Car, V. (2014), "Digital activism: digital media and civic engagement in Croatia", Southeastern Europe, Vol. 38 Nos 2/3, pp. 213-231.

Chen, W. (2014), "Taking stock, moving forward: the internet, social networks and civic engagement in Chinese societies", Information, Communication and Society, Vol. 17 No. 1, pp. 1-6.

Chen, Y.C. and Chang, T.W. (2020), "Explaining government's online transparency on collaborative policy platforms: risk management and configurational conditions", Public Performance and Management Review, Vol. 43 No. 3, pp. 560-586.

Chong, D. and Druckman, J.N. (2007), "A theory of framing and opinion formation in competitive elite environments”, Journal of Communication, Vol. 57 No. 1, pp. 99-118.

City of Turin (2019), "Example of sensitive analysis extraction applied to educational services through the Talkwalker platform", Zenodo, June 30, available at: http://doi.org/10.5281/zenodo.4670177 (accessed date January, 2021).

Clay, J.A. (2008), "Popular reporting", in Berman, E.M. (Ed.), Encyclopedia of Public Administration and Public Policy, 2nd ed., Taylor and Francis, New York, NY.

Cohen, S. and Karatzimas, S. (2015), "Tracing the future of reporting in the public sector: introducing integrated popular reporting", International Journal of Public Sector Management, Vol. 28 No. 6, pp. 449-460.

Cooper, D.J. and Sherer, M.J. (1984), "The value of corporate accounting reports: arguments for a political economy of accounting", Accounting, Organizations and Society, Vol. 9 Nos 3/4, pp. 207-232.

Del Gesso, C. and Romagnoli, L. (2020), "Citizen-centered reporting: assessing popular financial reporting practice in Italian decentralized governments", International Journal of Business and Management, Vol. 15 No. 2.

Dillard, J.F. and Ruchala, L. (2005), "The rules are no game: from instrumental rationality to administrative evil", Accounting, Auditing and Accountability Journal, Vol. 18 No. 5, pp. 608-630.

Dumay, J. and Dai, T. (2017), "Integrated thinking as a cultural control?", Meditari Accountancy Research, Vol. 25 No. 4, pp. 574-604.

Eccles, R.G. and Krzus, M.P. (2010), "Integrated reporting for a sustainable strategy: one report has the potential to significantly change how companies operate and investors think, shifting the focus from that of meeting short-term financial goals to developing a long-term business strategy that not only makes a commitment to corporate social responsibility, but also to a sustainable society", Financial Executive, Vol. 26 No. 2, pp. 28-33.

Ekins, P., Simon, S., Deutsch, L., Folke, C. and De Groot, R. (2003), "A framework for the practical application of the concepts of critical natural capital and strong sustainability", Ecological Economics, Vol. 44 Nos 2/3, pp. 165-185.

Fordham, A.E., Robinson, G.M., Cleary, J., Blackwell, B.D. and Van Leeuwen, J. (2018), "Use of a multiple capital framework to identify improvements in the CSR strategies of Australian resource companies", Journal of Cleaner Production, Vol. 200, pp. 704-730.

GASB (1992), "Research Report GR16 Popular Reporting: Local Government Financial Reports to the Citizenry, by Carpenter and Sharp (February)".

Gibbon, M. and Pokhrel, D. (1999), "Social network analysis, social capital and their policy implications", PLA Notes, Vol. 36, pp. 29-33.

Gonzalez-Zapata, F. and Heeks, R. (2015), "The multiple meanings of open government data: understanding different stakeholders and their perspectives", Government Information Quarterly, Vol. 32 No. 4, pp. 441-452.

Guthrie, J., Manes-Rossi, F. and Orelli, R.L. (2017), "Integrated reporting and integrated thinking in Italian public sector organisations", Meditari Accountancy Research, Vol. 25 No. 4, pp. 553-573. 
Guy, M.E. and Mastracci, S.H. (2018), "Making the affective turn: the importance of feelings in theory, praxis, and citizenship", Administrative Theory and Praxis, Vol. 40 No. 4, pp. 281-288.

Jönsson, S. (2010), "Interventionism-an approach for the future?", Qualitative Research in Accounting and Management, Vol. 7 No. 1, pp. 124-134.

Jordan, M.M., Yusuf, J.E., Berman, M. and Gilchrist, C. (2017), "Popular financial reports as fiscal transparency mechanisms: an assessment using the fiscal transparency index for the citizen user", International Journal of Public Administration, Vol. 40 No. 8, pp. 625-636.

Kalinina, O. and Valebnikova, O. (2017), "Human capital management as innovation technologies for municipal organization", Energy Management of Municipal Transportation Facilities and Transport, pp. 1315-1322.

Karatzimas, S. (2020), "The beneficial role of government accounting literacy in developing participatory citizens", Accounting Education, Vol. 29 No. 3, pp. 229-246.

Lee, M. (2006), "The history of municipal public reporting", International Journal of Public Administration, Vol. 29 Nos 4/6, pp. 453-476.

Liu, B. (2015), Sentiment Analysis: Mining Opinions, Sentiments, and Emotions, Cambridge University Press, Cambridge, United Kingdom.

Lukka, K. and Suomala, P. (2014), "Relevant interventionist research: balancing three intellectual virtues", Accounting and Business Research, Vol. 44 No. 2, pp. 204-220.

Manes Rossi, F., Brusca, I. and Aversano, N. (2018), "Financial sustainability as a driver for transparency and E-democracy: a comparative study in Italian and Spanish local governments", International Journal of Public Administration, Vol. 41 No. 1, pp. 22-33.

Manes-Rossi, F. (2019), "New development: alternative reporting formats: a panacea for accountability dilemmas?", Public Money and Management, pp. 1-4.

Manes-Rossi, F., Aversano, N. and Polcini, P.T. (2019), "Popular reporting: learning from the US experience", Journal of Public Budgeting, Accounting and Financial Management, Vol. 32 No. 1, pp. 92-113.

Manes-Rossi, F., Nicolò, G. and Argento, D. (2020), "Non-financial reporting formats in public sector organizations: a structured literature review", Journal of Public Budgeting, Accounting and Financial Management, Vol. 32 No. 4, pp. 639-669.

Mouffe, C. (2013), Agonistics: Thinking the World Politically, Verso Books, London; New York, NY.

Piotrowski, S., Grimmelikhuijsen, S. and Deat, F. (2019), "Numbers over narratives? How government message strategies affect citizens' attitudes", Public Performance and Management Review, Vol. 42 No. 5, pp. 1005-1028.

Power, M. (1992), "After calculation? Reflection on critique of economic reason by André Gorz", Accounting, Organizations and Society, Vol. 17 No. 5, pp. 477-499.

Puddu, L., Rainero, C., Secinaro, S., Indelicato, A. and Vietti, M.C. (2013), "The consolidated financial statement: are Ipsas and national accounting standards comparable? The Turin city council case", International Journal of Business and Social Science, Vol. 4 No. 13, pp. 241-250.

Queiroz, B.L. and Golgher, A.B. (2008), "Human capital differentials across municipalities and states in Brazil”, Population Review, Vol. 47 No. 2, pp. 25-49.

Royo, S., Pina, V. and Garcia-Rayado, J. (2020), "Decide Madrid: a critical analysis of an award-winning e-participation initiative", Sustainability, Vol. 12 No. 4, p. 1674.

Secinaro, S., Brescia, V., Iannaci, D. and Jonathan, G.M. (2021), "Does citizen involvement feed on digital platforms?”, International Journal of Public Administration, doi: 10.1080/01900692.2021.1887216.

Steccolini, I. (2019), "Accounting and the post-new public management", Accounting, Auditing and Accountability Journal, Vol. 32 No. 1, pp. 255-279.

Stoker, G. (2006), "Public value management: a new narrative for networked governance?", The American Review of Public Administration, Vol. 36 No. 1, pp. 41-57. 
Stone, G.W. and Lodhia, S. (2019), "Readability of integrated reports: an exploratory global study", Accounting, Auditing and Accountability Journal, Vol. 32 No. 5, pp. 1532-1557.

Tenney, M. and Sieber, R. (2016), "Data-driven participation: algorithms, cities, citizens, and corporate control”, Urban Planning, Vol. 1 No. 2, pp. 101-113.

Thomson, I. and Bebbington, J. (2004), “It doesn't matter what you teach?”, Critical Perspectives on Accounting, Vol. 15 Nos 4/5, pp. 609-628.

Woolcock, M. and Narayan, D. (2000), "Social capital: implications for development theory, research, and policy", The World Bank Research Observer, Vol. 15 No. 2, pp. 225-249.

Yusuf, J.-E.W. and Jordan, M.M. (2012), "Effective popular financial reports: the citizen perspective", Journal of Government Financial Management, Vol. 61 No. 4, pp. $44-49$.

Yusuf, J.E., Jordan, M.M., Neill, K.A. and Hackbart, M. (2013), "For the people: popular financial reporting practices of local governments", Public Budgeting and Finance, Vol. 33 No. 1, pp. 95-113.

Zambo, F. and Beltrachi, G. (2016), "City of Turin's (Italy) Populaf Financial Reporting is credit positive”, Moody's Public Sector Europe.

\section{Further reading}

Baccarne, B., Evens, T. and De Marez, L. (2020), "Understanding civic crowdfunding as a mechanism for leveraging civic engagement and urban innovation", Technology Innovation Management Review, Vol. 10 No. 5, pp. 51-66.

\section{Corresponding author}

Giuseppe Grossi can be contacted at: giuseppe.grossi@hkr.se

For instructions on how to order reprints of this article, please visit our website: 